\title{
Psicologia e inclusão: aspectos subJetivos de UM ALUNO PORTAdor DE DEFICIÊNCIA MENTAL ${ }^{1}$
}

PSYCHOLOGY AND SCHOOL INCLUSION: SUBJECTIVE ASPECTS OF A STUDENT WITH MENTAL DISABILITY

RESUMO: este trabalho teve como objetivo explorar a configuração de sentidos de um aluno portador de necessidades especiais mentais acerca do processo de inclusão escolar. Para tanto, foi participante desta pesquisa um aluno adolescente de 16 anos de idade portador de deficiência mental, matriculado na $7^{\mathrm{a}}$ série do Ensino Fundamental da Rede Regular. Como recursos para coleta de informações o delineamento de estudo de caso mostrou-se adequado, priorizando-se os sistemas conversacionais firmados com o aluno durante sete meses. As informações obtidas foram elencadas em categorias de indicadores significativos. Pôde ser constatado que uma das maiores barreiras a ser transposta pelo aluno no processo de inclusão escolar diz respeito à organização simbólica da própria instituição escolar, que atrelada aos padrões massificadores do desenvolvimento humano, vem a se estruturar muito mais como uma prática social e compensatória do que formadora ao aluno, ao dimensionar sua diferenciação e não considerar adequadamente sua singularidade.

PALAVRAS-CHAVES: subjetividade; necessidades especiais; inclusão; educação especial.

\begin{abstract}
: this article explored the configuration of a student with mental disability's feelings during the process of school inclusion. To achieve this objective, a sixteen-year-old student with mental disability who was enrolled in the seventh grade of a public elementary school participated in this research study. The delineation of the case study was deemed adequate as a resource for collecting information. The main research procedures were conversation sessions with the student undertaken during the seven months of investigation. The information collected was listed by categories of significant indicators. The study showed that one of the greatest barriers to be overcome in this process referred to the symbolic organization of the school, which, along with the generalizing patterns of human development, comes to structure itself much more as a social and compensatory practice than one that fostered the student's preparation. This organization focuses on how different the student is, instead of appreciating his uniqueness.
\end{abstract}

KEYWORDS: subjectivity; special needs; inclusion; special education.

\section{INTRODUÇÃo}

Políticas públicas inclusivas: a inclusão de uma nova escola

A proposta de inclusão escolar fortemente realçada por diretrizes e normas nacionais (BRASIL, 1988; BRASIL, 1990) e internacionais (ONU, 1990) é um dos maiores movimentos que vem exigindo mudanças na forma de compreender e estruturar os setores sociais. Para tanto, a Educação se torna um

${ }^{1}$ Texto produzido a partir de resultados parciais de pesquisa realizada no Programa de Pós-Graduação StrictuSensu em Psicologia Escolar da Pontifícia Universidade Católica de Campinas - PUCCAMP - Agradeço o apoio financeiro oferecido pelo CN Pq para a conclusão desta pesquisa

2 Mestre em Psicologia Escolar (PUC-Campinas), Doutoranda do Programa de Pós-Graduação em Psicologia como Profissão e Ciência (PUC-Campinas). - claudiagomes.psi@ bol.com.br

${ }_{3}^{3}$ Pontifícia Universidade Católica de Campinas. - gonzalezrey@terra.com.br 
eixo potencial izador de ações eatitudes mais democráticas, justas e igualitárias. E é na proposta de inclusão escolar de alunos com necessidades especiais que a discussão ganha foro e também deflagra as carências e os desafios sociais que historicamente permearam, deixando atéhoje resquícios marcantes da ineficiência das políticas educacionais em nosso país.

De acordo com a Declaração de Sal amanca (ONU, 1994), documento magno da ind usão escol ar, a construção de uma sociedade inclusiva éum processo de fundamental importância para a manutenção de um Estado Democrático. É este princípio que o Brasil busca partilhar com a implementação de suas ações educacionais inclusivas, e que tomam forma na formulação das Novas Leis de Diretrizes e Bases da Educação (BRASIL, 1996), e que mais recentemente são princípios reafirmados com a implementação das N ovas Diretrizes Curriculares para a Educação Especial no país (BRASIL, 2001).

Diferentes estudos internacionais já enfocaram os aspectos mais explícitos que dificultam o processo de inclusão de alunos com necessidades especiais nas escolas. Dentre os vários aspectos abordados ainda é unânime a falta de capacitação profissional adequada, a falta de recursos e materiais apropriados, as barreiras arquitetônicas efísicas, as barreiras humanas atitudinais quepermeiam as práticas pedagógicas em relação à inclusão, dentre outros (ERIC, 2002).

O quesevem percebendo équeessas deficiências passam a se constituir em barreiras secundárias ao se considerar o distanciamento existente entre a legalidade o objetividade das políticas educacionais inclusi vas e a realidade vivida nas ações educacionais reais quea escola desenvolve. Pesquisas como Emilio (2004), Franca (2005) eCrespo (2005), finalizadas recentementee que abordaram o contexto educacional e suas deficiências frente a proposta educacional inclusiva, apontam as diferentes formas que as barreiras para um processo inclusivo parecem polarizar a discussão da contextualização dos valores mais implícitos da proposta: clima escolar; as resistências, que por ventura possam ser vivenciadas pel os protagonistas envolvidos; uma formação acadêmica satisfatória relacionada a reflexão e abordagem das diferenças; aos ruídos familiares; assim como, da prática e necessidade latente dos encaminhamentos que são solicitados no panorama do processo de inclusão escolar de alunos com necessidades especiais.

De modo geral, diversos estudos da proposta de inclusão escolar parecem alertar para uma maior importância e atenção na implementação das políticas enfatizando assim que a proposta só será efetivada com sucesso quando compreendida como conseqüência de uma discussão da necessidade de mudança do paradigma educacional vigente. Esta mudança de paradigma devevir a enfatizar um maior compromisso com a diversidade humana, com as transformações das representações quanto ao outro, a diferença, a diversidade, tão arraigadas em nossos contextos escolares (BASTOS, 2003; CARMO, 2000; PRETTO, 2002; PESSI NI, 2002). 
Inclusão Escolar de alunos com necessidades especiais: aportes da Teoria da Subjetividade de Gonzalez Rey

De acordo com Gonzalez Rey (2003), a subjetividade pode ser definida, “como a organização dos processos de sentido e significação que aparecem e se organizam de diferentes formas eem diferentes níveis do sujeito ena personalidade, assim como nos diferentes espaços sociais em que o sujeito atua" (2003, p.108).

Segundo o autor (2004), a abordagem da subjetividade sob este novo prisma, possibilita a compreensão da esfera psicológica, dentro de uma análise complexa, recursiva e multidimensional, ao dotar uma simultaneidade do espaço social e do espaço individual, que rompe com a dicotomia e resgata a processual idade necessária para a compreensão do desenvolvimento humano de aluno em processo de inclusão escolar. As características de um sistema complexo, como podeser caracterizado o concei to de subjetividade, se refere à recursividade entre as configurações, a permanenteemergência de novos elementos precedentes da ação do sujeito, "a configuração de novas qualidades a partir das contradições econfrontações do sistema em seu desenvolvimento, a coexistência do diferenciado, do singular, como momento constituinte do sistema, entre outros aspectos caracterizadores da subjetividade" (GONZALEZ REY, 2005, p.37).

De acordo com Martinez (2005), a subjetividade encarada ao mesmo tempo como significados e sentidos, caracterizadores também dos diferentes espaços sociais que os indivíduos constituem, contribui no sentido de romper com as dicotomias individual/ social, interno/ externo, intra-subjetivo/ intersubjetivo, articulando dialeticamente ambos os pólos, e expressando seu caráter complementar, contraditório e recursivo.

É nessa intersecção individual/ social, que os desafios no estudo da subjetividadetornam-se acirrados, uma vez que não se pode considerar a exclusão entre os processos individuais e sociais, pois implicam reciprocamente na constituição subjetiva do individuo e de sua sociedade (GONZA LEZ REY, 2002). A compreensão da subjetividade de alunos com necessidades especiais vem a desafiar o estudo do processo de inclusão escolar, pois como se sabe são sujeitos quehá muito são reféns deatribuições econfigurações sociais queos desconsideram como sujeitos ativos e construtores.

Segundo Gonzalez Rey (2005), o sentido subjetivo podeser compreendido como uma complexa combinação de emoções e processos simbólicos, vivenciados em diferentes momentos e diversas esferas processuais da vida dos sujeitos. Em suas palavras: pode ser definido ainda, "toda a emoção que se integra em uma cadeia de produção de emoções em qualquer espaço da vida humana (...), não se reprime, enão atua como uma entidade invariável, mas como uma processualidade constante" (2005, p 14).

Ainda de acordo com o autor, o sentido subjetivo flui na subjetividade sob formas distintas, e tem como características centrais, sua infinita versatilidade, 
uma ação constante recursiva, e nunca podem ser consi derados padronizadores, uma vez, que denotam a existência singular eo caráter especifico da subjetividade individual. O autor ressalta ainda, que os sentidos subjetivos nunca podem ser considerados como reflexos de uma ação direta social, pois se caracteriza por definição por uma produção sistêmica subjetiva.

Os sentidos expressariam direções de contato econvergência entre um "eu e um outro ou vários outros", preservados em suas singularidades e diferenciações, mantendo sistemas individuais e singulares. Tratar da capacidade do sujeito de configurar sentidos vem a dotar o indivíduo a uma nova deforma de atuação em seu próprio desenvolvimento, não como correspondência linear às exigências externas, mas como ativo tanto na correspondência dessas exigências como construtor nas premissas que a mantêm.

Explorar o sentido subjetivo nos seus intercâmbios com a subjetividade social parece, portanto, uma das formas mais efetivas de resgatar o indivíduo em seus sistemas de linguagem, não como reflexo ou correspondência linear a um mundo objetivo - "do outro", mas sim como possibilidade de articular um mundo paral el o - "do eu", como organização própria e singular, que posteriormente, possa ser significado dentro de uma esfera social.

Portanto éno perpasso subjetividadesocial esubjetividadeindividual que a singularidade dos sujeitos deve ser considerada, e somente assim, com o realce deseu desenvolvimento, como sujeito individual, éque poderão ser geradas novas redes de relações sociais, que poderão atuar na transformação das redes anteriores. O resgate aos alunos com necessidades especiais como "sujeitos" não mais formatados em estereótipos delimitadores é a base para a configuração de novos sentidos sociais e individuais, que alavanquem suas identidades, gerando novas configurações sociais e individuais, com ações e valores próprios.

Para tanto, este trabal ho a luz da Teoria da Subjetividade de Gonzalez Rey tem como objetivo explorar os sentidos subjetivos de um aluno portador de deficiência mental acerca do seu processo de inclusão escolar.

\section{Metodologia}

Deacordo com Gonzalez Rey, torna-se deextrema necessidadeo avanço na compreensão da complexidade da ação social dos sujeitos. O processo de configuração desentidos subjetivos é histórico emediado, e exigeformas deestudo que dêconta da dial ogicidade, contradição erecursividade das questões subjetivas, model o este denominado pelo autor como epistemologia qualitativa, que tem como foco a busca pela:

[...] produção de conhecimento em psicologia que permita a criação teórica acerca da realidade plurideterminada, diferenciada, irregular, interativa e histórica, que representa a subjetividade humana. (GON ZALEZ REY, 2002, p.38). 
Para tanto, o desenvolvimento de uma pesquisa respaldada pela epistemologia qualitativa apresenta três princípios fundamentais a serem considerados: 1) ênfaseno conhecimento como produção construtiva interpretativa: necessidade de dar sentido a expressões do sujeito estudado; 2) significação da singularidade como nível legítimo da produção do conhecimento: resgate a individualidade/ singularidade; e 3) caráter interativo do processo de produção do conhecimento: relações pesquisador/ pesquisado.

Participante e local da pesquisa: o participante central desta pesquisa foi um aluno adolescente portador de deficiência mental com 16 anos de idade e matriculado na 7ạ série do Ensino Fundamental da Rede Regular de Ensino de uma cidade da Grande São Paulo / SP.

Tanto a escolha do participante central para esteestudo como a escolha da instituição escolar para a realização da pesquisa, se deu pelo critério de conveniência da pesquisadora, queapós um levantamento dos alunos matriculados na rederegular da região de acordo com a Diretoria de Ensino da região priorizou o acompanhamento da referida instituição com base no critério de proximidade da localização da escola o que facilitou o processo de pesquisa.

Recursos: todas as informações obtidas foram anal isadas e organizadas dentro de um modelo de pesquisa dassificado de estudo de caso, pois se trata de um delineamento metodológico de essencial importância ao propiciar o estudo de relações e tensões entre o individual e social, foco de trabal hos que visualizam a exploração da subjetividade humana. Para tanto, os Sistemas Conversacionais que segundo Gonzalez Rey, permitem ao pesquisador deslocar-se do lugar central das perguntas e defato integrar-sea dinâmica natural deconversação com o pesquisado, foi um recurso considerado de essencial importância para a qualidade e amplitude dos relatos (emocionalidade, expressões verbais e corporais, idealizações, perspectivas, entre outros), em diferentes momentos (atividades em sala de aula, atividadesem reuniões, horário deintervalo, etc). Para tanto, tornou-seimprescindível à utilização da modal idade metodológica deum diário de pesquisa, que segundo Flick (2004), não representa apenas uma finalidade de transcrição de informações, mas sim, é fundamental para a reflexão sobre o processo de pesquisa, imprescindível para o estudo dos sentidos subjetivos do aluno em processo de inclusão escolar.

Procedimentos: os sistemas conversacionais foram firmados entre a pesquisadora e o participante, direcionados com a devida exploração e o aprofundamento nos níveis de discursos ou narrativas construídas, durante sete meses, no período de agosto/ 2004 à abril/ 2005, que total izaram 28 semanas, de coleta de informações, obtidas nas visitas realizadas pela pesquisadora, três vezes por semana, nos períodos das 7:00h às 12:00h, e das 13:00h às 17:00h.

Vale ressaltar que foi previamente firmado um contato com a direção da escola a fim da obtenção da autorização foi entregue ao participante e ao seu responsável legal Termo deConsentimento LivreeEsclarecido quanto as questões éticas da pesquisa. 
A nálise das Informações: as informações obtidas por meio dos diferentes recursos foram organizadas e traduzidas pela construção de indicadores de inteligibilidade, que buscaram avançar na compreensão dos sentidos subjetivos do aluno acerca do processo de inclusão escolar. A significação dos trechos, não como um processo arbitrário do pesquisador, mas sim como uma ação interpretativa-construtiva teve sua legitimidade quando associada ao desenvolvimento de zonas de sentido, que ampliaram e avançaram a significação do objetivo lançado pelo trabal ho investigativo (GONZA LEZ REY, 2005).

\section{Resultados e discussão}

Ao explorar a inclusão escolar de um aluno portador de deficiência mental, uma compreensão efetiva deve ser assumida à caracterização conceitual atribuída a esta necessidade especial. Porém, não uma conceitualização que despersonalize o sujeito ao enfocar sua idade mental ou suas habilidades cognitivas. A última revisão da defini ção do conceito de deficiência mental (LUCKASSON et al., 1994) vem a realçar não mais os graus de comprometimento intelectual, mas sim o ajustamento entre as capacidades dos indivíduos eas estruturas eexpectativas do meio em que vivem, aprendem e trabalham. Desta forma, tem-se claro que nenhum modelo educativo pode ignorar as características de funcionamento das pessoas que apresentam incapacidades sem considerar a interação destas com o meio. No entanto, como relatos indicados a seguir, pôde-se constatar que, deforma geral, não é esta a compreensão atribuída ao al uno portador de deficiência mental em seu processo de escolarização.

Pode ser percebido que, se por um lado, a instituição parece desprezar as potencialidades do aluno participante da pesquisa, por outro lado, há uma necessidade de adaptá-lo as ações pré-concebidas a respeito do ritmo e da natureza do processo de aprendizagem tento como base a descrição de sua necessidade especial. Compreensões estas confirmadas pelo próprio aluno ao referenciar seus diálogos com os seus professores, "ele (professor) fala quando alguém pergunta: não tem como trabalhar com ele, não faz nada, é muito bom para ajudar no trabalho pesado... mas aprende não tem como... é clara a deficiência"; ou ainda diálogos de sua família " minha irmã também fala: como vai aprender não faz nada, só quer brincar e a preguiça, não quer nada com nada mesmo, faz alguma lição? Claro que não... nunca vai aprender".

Expressões estas que puderam ser discutidas com o al uno e que vieram a indicar que, diferentemente de seus professores ou desua própria família, o al uno configurava sentidos subjetivos acerca do seu processo de inclusão escolar atrelados a uma necessidade e motivação de seu desenvolvimento educacional (traduzido por ele próprio por uma necessidade de aprender a ler ea escrever), que indicavam ainda, aspirações e desejos por uma carreira profissional, como segue em um de seus relatos: "Tenho muita vontade de ler e escrever, eu quero apren der.... "eu venho para aprender, só que só sei al gumas lições, outras são difíceis, daí não faço nada, mas preciso ler e escrever porque quero ser policial, e tem que estudar bastante para ser policia". 
De acordo com Gonzalez Rey (1995), o desenvolvimento e a transformação do sujeito são embasados na contradição entre o social eo individual. Dos impasses entre o individual, considerado pelo posicionamento construtor do individuo, e o social. N ota-se, que na instituição escolar na qual o aluno vem buscando se desenvolver estão sendo compartilhadas apenas representações que tendem a desconsiderá-lo como sujeito ativo de suas próprias construções educacionais, profissionais e sociais. São esses sentidos tão singulares do aluno acerca de seu processo de escolarização permead os pela contraditória organização simbólica da instituição escolar quefundem todo o seu desenvolvimento humano (GONZALEZ REY, 2003).

É neste embate entre os sentidos individuais e a consideração social que o processo de inclusão deste aluno parece paralisar-se. Se de um lado, tem desconsiderada suas potencialidades tanto pela escola como de sua família "P reciso aprender a ler e a escrever, mas ninguém me ensina de verdade... na conta eu sou bom mas o professor de matemática não me ensina mais", por outro lado, busca compreender o tratamento exclusivo e desigual que parece desprezá-lo como al uno. "só eu saio a hora que quero, só duas professoras que não deixam, mas eu saio, grito, não faço lição, mas passo de ano, aprender a ler e a escrever é aqui na escola, mas como eu não sei não preciso ficar na sala, mas agora se você me ensinar eu posso fazer lição na sala também".

Entretanto, é neste mesmo ambiente, que cada vez mais se contrapõe ao resguardo das singularidades e diversidades dos alunos, que o processo de inclusão escolar de alunos portadores de necessidades especiais vem sendo desenvolvido, "só os mel hores alunos sentam-se nas carteiras próximas ao professor, eu

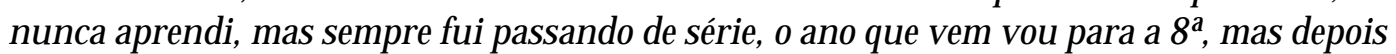
não passo mais direto, e como não sei nada, não sei o que vou fazer"- relato este, realizado pel o al uno, eque mais uma vez, vem a marcar o abismo existente para a efetivação de uma educação de fato inclusiva para todos.

O resgate das subjetividades vem realçar a reinserção dos sujeitos com de necessidades especiais não mais compreendidos como passivos, mas sim impulsionados como construtores e constituintes efetivos das relações sociais, entre elas em destaque as relações institucionais e escolares (OROFIN O; ZANELLO, 1999).

Torna-se daramenteconstatado queas barreiras a serem transpostas pelo aluno portador de necessidades especiais, aqui na figura do aluno portador de deficiência mental, parecem decorrentes não de seu déficit intelectual ou cognitivo, fundantes enão limitadores deseu desenvolvimento, como considerado pelo próprio aluno: "eu não sei, mas eu acho que consigo aprender, tem muita coisa, mas eu acho quevou conseguir" , mas são sim barreiras, prioritariamente, decorrentes de sentidos sociais, embasados, fortemente, em uma tendência padronizadora deconsiderar os sujeitos, como ainda relatado pelo próprio al uno: “eu não sei, al guns professores já meensinaram, agora largaram, mas eu ainda não sei nada, tem gente que fala que eu não aprendo por causa da cabeça, é que eu esqueço tudo, mas a conta eu não esqueci, né?" . 
Deacordo com Gonzalez Rey (2003, p.241), “a subjetividadeindividual mostra os processos de subjetivação associados à experiência social do sujeito concreto, assim como as formas de organização desta experiência por meio do curso da história do sujeito". A ssim, com a devida consideração ao sujeito em sua historicidade, a linearidade, há muito considerada, embasada na limitação do al uno com necessidades especiais, deixa de ser prioritária, constituindo-se, como delimitadora do desenvolvimento, evem a fundar a particularidadedesuas relações enquanto sujeito.

E, é este aluno atípico aos demais, e descaracterizado por sua diferenciação embasada na igualdade que o despersonaliza é que vem sendo, a pretexto, de um tratamento exclusivo dos profissionais da escola, de fato excluído. Fato que podeser constatado ao se explorar, especificamente, al gumas observações erel atos real izados na escola quanto às funções prestativas esubalternas atribuídas ao aluno. A parentemente, caracterizações são atribuídas pelos professores e por muitos profissionais da escola, quanto às funções prestativas que o aluno desempenha na escola e são assumidas pelo aluno, como indicado no seguinte relato: "eu varro o pátio, varro a sala de aula, gosto de fazer as coisas na escola, gosto de ajudar o pessoal da merenda, eles falam que eu sou muito prestativo".

A incorporação destas atividades, pelo próprio aluno, como uma configuração de sentido atrelada a sua inclusão escolar, pode ser claramente evidenciada desde o primeiro contato da pesquisadora, que foi interrompido pelo aluno, com a justificativa, em suas próprias palavras: "agora eu não posso conversar tenho que varrer a sala de aula; eu tenho que ajudar a colar os cartazes, depois limpar a parede; acho que até no sábado vão ter que lavar a escola, e eu preciso aju dar também".

A função prestativa, quando relatada pelo aluno, é considerada como uma possibilidade de ajudar as outras pessoas, "eu ajudo para que depois elas me ajudem" expressão, que denota um agradecimento aos lanches querecebe, as roupas que lhe são dadas, as conversas que alguns professores dispensam com ele, ou seja, agradecimentos e ações consideradas até como caridosas, realizadas pela instituição e alguns profissionais da escola.

Estas avaliações, denominadas como prestativas, podem ser consideradas como uma "valorização subalterna do aluno", que, aparentemente, é extremamente arraigada à organização simbólica da escola. De acordo com Gonzalez Rey (2004, p.144), "toda produção de sentido é associada a uma configuração pessoal que tem uma história e um contexto social que se veicula de uma forma determinada diante da ação concreta de um sujeito". E mais uma vez, tornou-se evidente que o perpasso da subjetividade social (delimitadora do desenvolvimento educacional do al uno), vem a interpor-se, constantemente. É esta subjetividade social, que, necessariamente, precisa ser reconsiderada, não mais como fator externo em relação aos indivíduos, mas como processos implicados dentro de um sistema complexo do processo de inclusão escolar desses alunos. (GONZALEZ REY, 2004). 
A inda de acordo com o autor, somentenovas possibilidades derelações sociais virão a romper com a limitação e exclusão arraigados ao contexto escolar e social do aluno com necessidades especiais. Por meio de suas próprias ações, poderão ser geradas novas tramas sociais (GONZALEZ REY, 2003), entre elas, especificamente, novas tramas sociais escolares, que o considere e o compreenda como al uno portador não apenas denecessidades, mas sim desingularidades, como todo e qualquer sujeito.

\section{Considerações finaIS}

A o considerar-se o processo de inclusão do aluno portador de deficiência mental, pode-se constatar a percepção do processo de inclusão escolar amparada muito mais como uma prática social ecompensatória do que formadora acadêmica-profissional. Entretanto, podeser evidenciado queos sentidos subjetivos do próprio aluno, quando real çados, refletem uma singularidade não demarcada pela deficiência, mas sim por sua historicidade enquanto sujeito, com vontades, desejos e perspectivas próprias e singulares.

Frente a um espaço conversacional, que de fato enfatizou econsiderou as singularidades, os desejos, as aspirações do aluno, foi possibilitado a expressão de indicadores como: a busca pelo rompimento do espaço escolar limitado à sociabilização; a quebra das práticas compensatórias (ganho de recursos financeiros injustificados), o comprometimento com o desenvolvimento educacional e profissional, ações deautonomia, entreoutros, mostraram ser sentidos configurados pelos aluno em seu processo deinclusão escolar. No entanto, a compreensão desses sentidos foi inexistente dentro da instituição escolar.

Torna-se claramente constatado que a efetivação do processo de inclusão escolar do aluno portador de deficiência mental deve enfatizar não mais um desenvolvimento delimitado com base em sua deficiência, mas sim, objetivar tanto a valorização de papéis individuais e sociais, quanto à consideração desses sujeitos construtores e constituintes de suas relações sociais.

\section{REFERÊNCIAS}

BASTOS, M. B. Inclusão escolar: um trabalho com professores a partir de operadores da psicanálise. 2003. Dissertação (Mestrado em Psicologia) - Universidade de São Paulo, Instituto de Psicologia. São Paulo.

BRA SIL. Constituição da República F ederativa do Brasil. Obra col etiva de autoria da Editora Revista dos Tribunais. São Paulo: Editora Revista dos Tribunais, 1988. p.13563., 1990.

Estatuto da Criança e do A dolescente (Brasil, 8.069/90). Diário Oficial da União -

. Lei de D iretrizes e Bases da Educação. Disponível em www.mec.gov.br/ legis/ zip/ Iei9394/ sip.., 1996 
BRASIL. D iretrizes Curriculares para a E ducação Especial no Ensino R egular.www.mec.gov.br/ seep/ mec, 2001. A cesso em: 02 set. 2007.

CARM O, N. H. P ercepções de educadores quanto a inclusão e integração de crianças ejovens com necessidades especiais. 2000. $101 \mathrm{f}$. Dissertação (Mestrado em Psicologia da Educação) Pontifícia Universidade Católica de São Paulo. Psicologia da Educação. São Paulo. 2000.

CRESPO, T. C. F. Educação especial frente a inclusão de jovens e adultos: um estudo de caso. 2005. 79 f. Dissertação (Mestrado em Psicologia da Educação) - Pontifícia Universidade Católica de São Paulo. Psi cologia da Educação. São Paulo, 2005.

EMILIO, S. A. 0 cotidiano escolar pelo avesso: sobrelaços, amarras enós no process deinclusão. 2004. 265 f. Tese (Doutorado em Psicologia) - Universidade de São Paulo. Instituto de Psicologia, São Paulo, 2004.

ERIC. Including students with disabilities in general education classrooms. ERIC Disget. Online: <www.askeric.org/ databases/ ERIC_Digest/ ed358677.html>Acesso em: 8mar. 2002.

FRAN CA, C. C. Políticas deidentidade eestratégias identitárias: relflexões sobrea dinâmica de relações exclusão/ inclusão no contexto escolar. 2005. 262 f.Tese(Doutorado em Psicologia da Educação) - Pontifícia Universidade Católica de São Paulo, São Paulo, 2005.

FLICK, U. A n introduction qualitative research. London: Bookman, 2004.

GONZALEZ REY, F. Comunicación, personalidad y desarrollo. Havana: Puebloy Educación, 1995. . Pesquisa qualitativa em psicologia - caminhos e desafios. São Paulo: Thomson, 2002. . Sujeito e subjetividade. São Paulo: Thomson, 2003. . 0 social na psicologia e a psicologia social. São Paulo: Vozes, 2004.

. O Valor heurístico da subjetividade na investigação psicológica. In: _. . (Org).

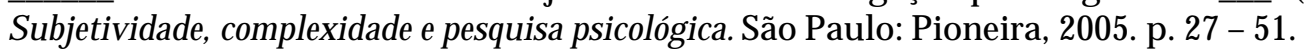

LUCKASSON, R. Retard mental: definition, classification et systemedesoutien. 9. ed. SaintHyacinthe: Edissem Inc, 1994.

MARTINEZ, A. M. Inclusão escolar: desafios para o psicólogo. In: MARTINEZ, A. M. Psicologia escolar e compromisso social. São Paulo: Alínea, 2005. p. 95-114.

ORGA NIZAÇÃ O DAS N AÇÕES UN IDAS (1990). D eclaração M undial sobre E ducação para Todos. Tailândia. Disponível: <www.educaçãoonline.pro.br>Acesso em: 20 set. 2001.

. (1994). Declaração de Salamanca sobrePrincípios Políticas e Práticas em Educação Especial. Salamanca. Disponível: <www.direitoshumanos.usp.br> acesso em 17 set. 2001. OROFINO A. M.; ZANELLO, V. A . A subjetividade social na escola. Brasília: Paralelo, 1999.

PESSINI, M. A. U m estudo qual itativo: al unos portadores de deficiência no ensino superior. 2002. 96 f. Dissertação (M estrado em Psicologia) - Pontifícia Católica do Rio Grande do Sul. Faculdade de Psicologia, Porto Alegre. 2002.

PRETTO, B. U m olhar psicanalítico sobrea inclusão decrianças com necessi dades edu cativas especiais em uma escola de ensino regular. 2002, 156 f. Dissertação (Mestrado em Psicologia) Universidade Federal do Rio Grande do Sul. Instituto de Psicologia, 2002.

Recebido em 05/ 06/ 2007

Reformulado em 10/ 10/ 2007

A provado em 25/ 03/ 2008 